\title{
Shunt malfunction in patients with hydrocephalus: complications revisited
}

\author{
Ajay Hegde, ${ }^{1}$ Rajesh Parameshwaran Nair, ${ }^{2}$ Sibhi Ganapathy, ${ }^{1}$ Lakshman I Kongwad ${ }^{1}$
}

'Department of Neurosurgery, Kasturba Medical College, Manipal, Karnataka, India ${ }^{2}$ Department of General Surgery, Kasturba Medical College, Manipal, Karnataka, India

\section{Correspondence to}

Dr Rajesh Parameshwaran Nair, rajeshnair39@yahoo.com

Accepted 14 December 2015

\section{DESCRIPTION}

The ventriculoperitoneal shunt has been the mainstay for definitive treatment of hydrocephalus since time immemorial. As such, several case reports describing the complications of this procedure have been documented in the literature over the past few decades. The spectrum ranges from ventricular catheter dislodgement to abdominal catheter end perforating the stomach and causing intussusception; several case illustrations have depicted the possible aftermath of this blind procedure. After the advent of neuronavigation and planning procedures on CT scans, the complication rates have significantly reduced.

Shunt malfunction, secondary to migration of the abdominal end, remains as one of the most common complications following ventriculoperitoneal shunting. ${ }^{1}$ Large bowel perforation is a rare complication with an incidence of $0.1-0.7 \% .^{2}$ In rare instances, there have been cases of herniation of the peritoneum along with the distal end of the catheter through a lax posterior rectus sheath. ${ }^{3}$ The unprecedented cases we describe, the first of a child and the other of an elderly woman, mandate a separate mention in the literature. We present our institutional experience, treatment dilemma, surgical management and outcomes in both the patients.

Case 1: A 1 1/2-year-old boy presented with intermittent appearance of the distal end of a ventriculoperitoneal shunt tube at the anus, while attempting to pass stools. The mother said that the child had been treated for obstructive hydrocephalus with a medium pressure Chhabra shunt, 9 months prior. On neurological examination, the child was active and alert; he had acquired appropriate milestones for his age and had no meningeal signs. The shunt chamber seemed to be functioning well. He was investigated with a shunt series X-ray, which revealed the distal end of the shunt tube traversing the entire lumen of the large intestine and ending in the sigmoid colon (figure 1A). A CT scan (brain CT) was ordered, which showed a significant

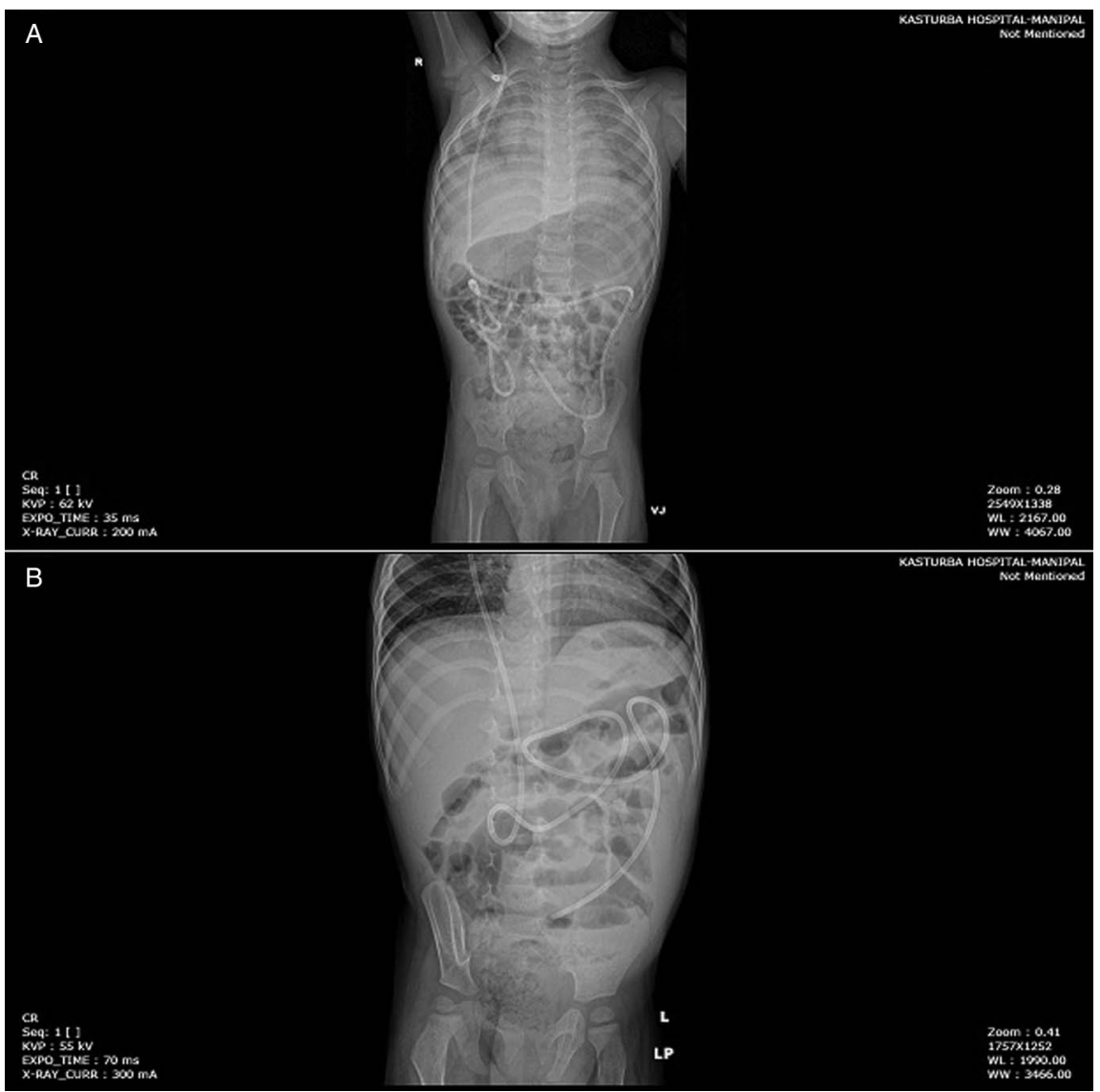

Figure 1 (A) Shunt series X-ray showing the distal end of the ventriculoperitoneal shunt traversing the caecum and the ascending colon into the transverse colon with the tip at the rectum. (B) Postoperative shunt series X-ray showing the revised distal end within the peritoneal cavity. 

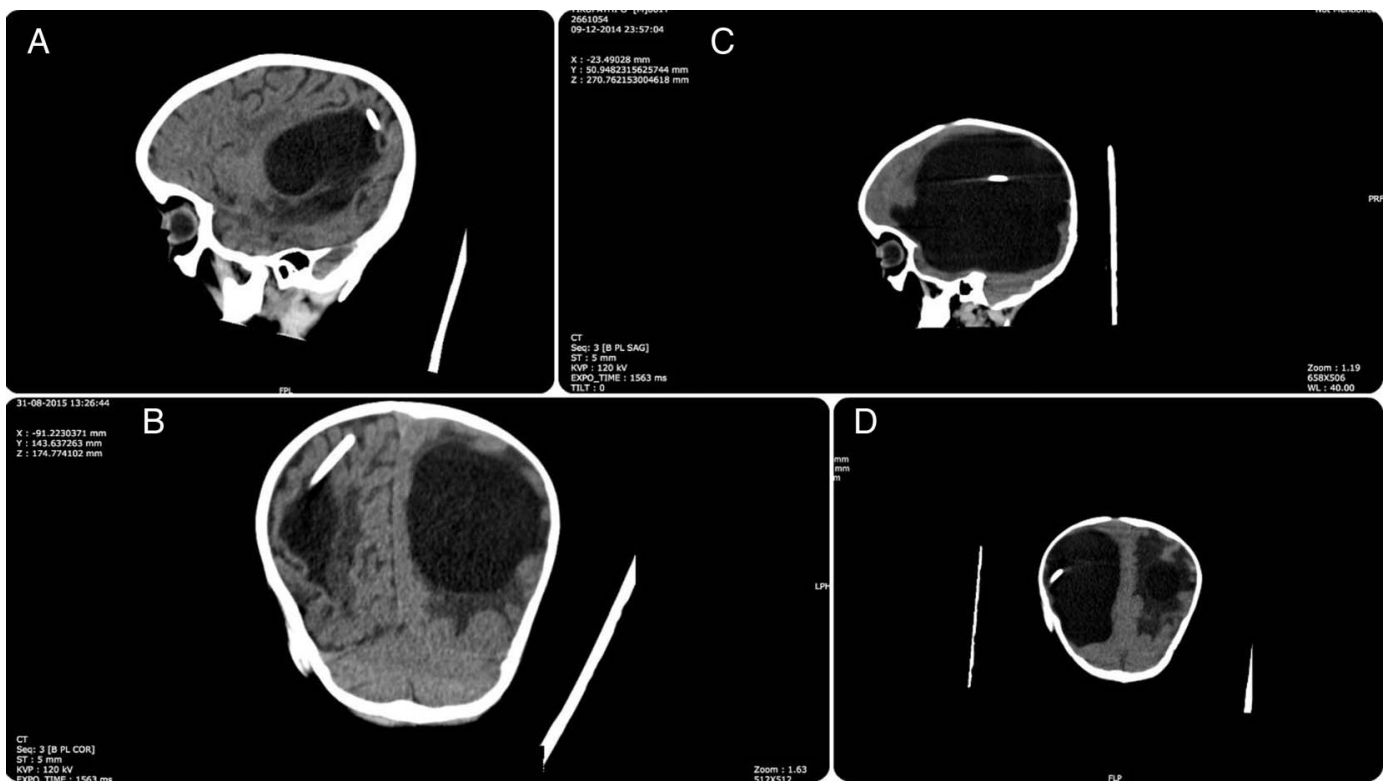

Figure $2 \mathrm{CT}$ of the brain (A) sagittal and coronal (B) section showing arrested hydrocephalus with the proximal ventricular catheter in situ. Postdistal end ligation (C) sagittal and (D) axial CT of the brain showing an increase in the ventricle size.

reduction in the size of the ventricle, with arrested hydrocephalus (figure 2A, B). The parents were counselled regarding the risk of meningitis and need for shunt revision.

Ascending infection was a priority, and the child was initially treated with a ligation and division of the shunt tube at the abdominal entry point. Copious cerebrospinal fluid (CSF) seemed to exude from the abdominal incision, and a repeat CT scan confirmed our fears. This was an indirect indicator of ongoing development of hydrocephalus (figure 2C, D). He was taken up for a shunt revision with colonoscopic extraction (figures 3 and 4) of the now dislodged distal shunt tube. Postoperatively, an X-ray series of the shunt was taken, which showed the abdominal end of the catheter in situ (figure 1B). The child had an uneventful recovery, was started on oral feeds and discharged after 1 week.

Case 2: A 68-year-old woman was shunted for normal pressure hydrocephalus (NPH). She presented to us 6 months postoperatively, with a reducible, painless swelling at the abdominal

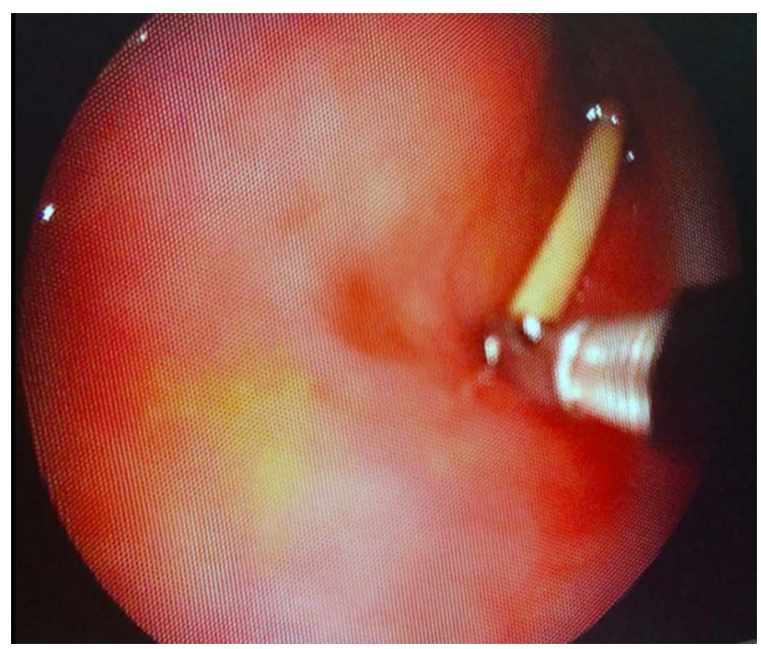

Figure 3 Colonoscopic view of the distal end of the shunt tube with biopsy forceps being used to grasp and retrieve the tube. incision site, which had impulse on coughing and straining. Clinical examination showed a non-tender, reducible swelling (approximately $5 \times 6 \mathrm{~cm}$, oriented longitudinally) at the abdominal insertion site of the shunt. Neurological examination was unremarkable and the shunt chamber seemed to be working well. A shunt series X-ray seemed to be normal and the patient was taken for shunt re-exploration and repositioning of the abdominal end of the shunt. A preoperative ultrasound was performed and disregarded, since it was unable to detect any defect in view of the significant abdominal fat that the patient possessed.

Intraoperatively, a thin-walled sac was seen in the subcutaneous tissue, with CSF and the shunt loop present within the hernial sac (figure 5). The neck appeared narrow, and the shunt tip was removed and reinserted into the peritoneum via a separate peritoneal incision.

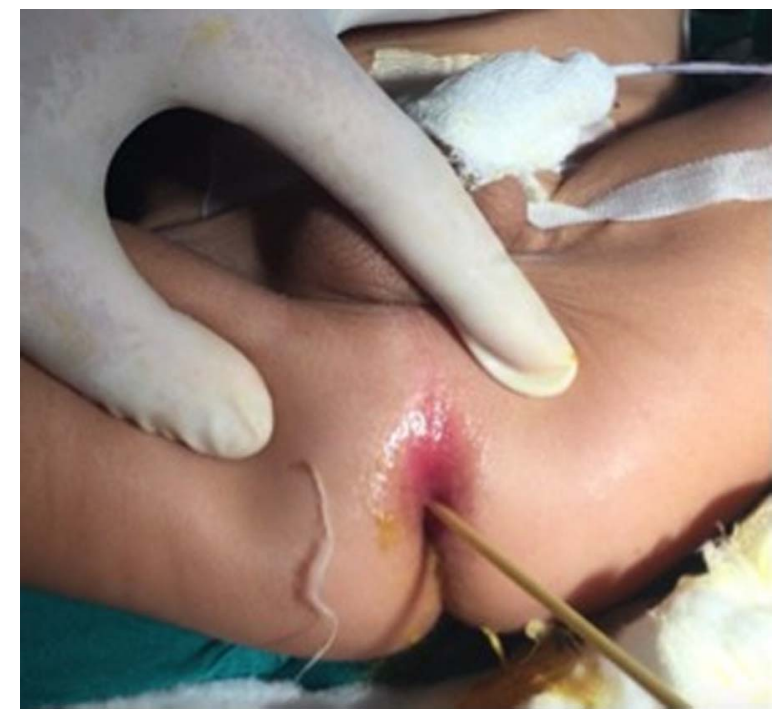

Figure 4 Per-anal extraction of the retrieved distal end of the ventriculoperitoneal shunt. 


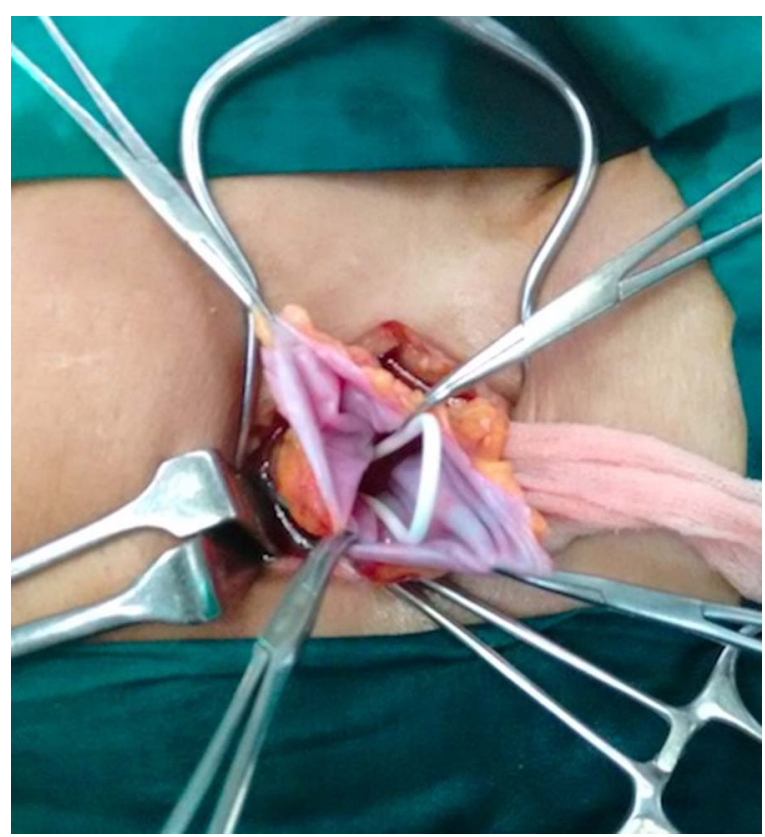

Figure 5 Intraoperative image showing the looped distal end of the shunt within the now opened hernial sac.

We now believe that the patient had had no neurological deficits since the CSF was draining into the hernial sac, with no evidence of hydrocephalus. Moreover, she was a case of NPH, the symptoms of which were controlled with minimal drainage of CSF into the hernial sac and from there into the peritoneal cavity. The examination findings corroborated this theory, since the sac was compressible and presented on straining.

Definitive treatment for a hernia was also carried out. The hernial sac neck was ligated with a prolene purse string suture and the rectus was double breasted over the defect. A prolene $(5 \times 7 \mathrm{~cm})$ mesh was placed over the deficient area and restrengthened with stay sutures. Postoperatively, the patient did well and was discharged after 1 week.

\section{Learning points}

- In the rare event of a patient presenting with signs and symptoms of a hernia, one should consider the possibility of a hernia sac containing the distal end of the tube, as in our case.

- Shunt-related complications need not always present with hydrocephalus and shunt failure.

- The shunt X-ray series may appear normal in some cases, but if suspicious images appear postoperative, the patient mandates re-exploration and shunt revision.

- In case of re-exploration and revision of the abdominal end, it is important to reinsert the distal end through a separate peritoneal incision.

Twitter Follow Ajay Hegde at @ajayhegde

Contributors AH was involved in data collection. RPN was responsible for write up and revisions. SG was responsible for write up. LIK participated in final approval.

Competing interests None declared.

Patient consent Obtained.

Provenance and peer review Not commissioned; externally peer reviewed.

\section{REFERENCES}

1 Ghritlaharey RK, Budhwani KS, Shrivastava DK, et al. Trans-anal protrusion of ventriculo-peritoneal shunt catheter with silent bowel perforation: report of ten cases in children. Pediatr Surg Int 2007;23:575-80.

2 Sathyanarayana S, Wylen EL, Baskaya MK, et al. Spontaneous bowel perforation after ventriculoperitoneal shunt surgery: case report and a review of 45 cases. Surg Neurol 2000;54:388-96.

3 Chung J, Yu J, Joo HK, et al. Intraabdominal complications secondary to ventriculoperitoneal shunts: CT findings and review of the literature. AJR Am J Roentgenol 2009;193:1311-17.

Copyright 2016 BMJ Publishing Group. All rights reserved. For permission to reuse any of this content visit http://group.bmi.com/group/rights-licensing/permissions.

BMJ Case Report Fellows may re-use this article for personal use and teaching without any further permission.

Become a Fellow of BMJ Case Reports today and you can:

- Submit as many cases as you like

- Enjoy fast sympathetic peer review and rapid publication of accepted articles

- Access all the published articles

- Re-use any of the published material for personal use and teaching without further permission

For information on Institutional Fellowships contact consortiasales@bmjgroup.com

Visit casereports.bmj.com for more articles like this and to become a Fellow 